\title{
SYNTHESIS OF PLANTWIDE QUALITY PREDICTION SYSTEM FOR A SINTERING PLANT
}

\author{
Michael Langer, Birgit Vogel \\ University Wuppertal, automation and process control engineering, \\ Fuhlrottstraße 10, 42119 Wuppertal, Germany \\ e-mail: langer@uni-wuppertal.de
}

\begin{abstract}
To substantially improve operational control of complex industrial plants, it is important to be able to predict the influences which process variables have on qualityrelevant target variables. The determination of influencing relationship and also the delay-time behaviour of various industrial processes makes it difficult to synthesis a quality prediction system. A hybrid modeling method combined with a suitable classification of process characteristics ensures a widespread model synthesis for quality prediction.

Copyright (C) 2002 IFAC.
\end{abstract}

Keywords: process control, Neuro-Fuzzy, modeling, design, simulation

\section{INTRODUCTION}

There are various industrial processes, which are distiguished by complex physical and/ or chemical relationships. Such processes are often supervised manually by operator. Target objective for operational control is cost effective production with reduced range of fluctuation in process operations and minimisation of power consumption. Beside a complex relationship between influencing- and quality target variables, several processes have a large delay-time behaviour in hour range. For this reason the operation control of the plant requires operators with widespread experience. An effective quality prediction system which facilitate the operators work would be a desireable improvement. To implement such a quality prediction system, methods of automation- and modeling techniques are combined.

A suitable classification of process characteristics ensures a model synthesis of quality prediction systems for a special class of industrial processes. In this paper, a process classification and implementation of such a quality prediction system for an iron ore sintering plant ${ }^{1}$ is presented.

\section{PROJECT OBJECTIVES}

In this paper a strategy for process classification is developed, which makes it possible to identify certain industrial processes. The process classification purpose will be realized by determination of unique process characteristics.

A suitable strategy for classification allows a generalization of a modeling technique for the realization of quality prediction systems for a special class of processes. Due to this goal, a sintering process for iron ore will be characterized with the developed strategy and a model based prediction system for sinter quality will be implemented which assists the operator in process control. A model assisted process control will be improved in such a manner, that a uniform processing is achieved. The modeling technique, which is used for realization of the sinter quality prediction system, is also available for industrial processes which are classified with the developed table of characteristics.

1. a burden preparation process from the smeltery industry 


\section{PROCESS CLASSIFICATION BY CHARACTERISTICS}

In order to describe a wide spread of industrial processes, their classification will be realized under consideration of high level of abstraction. Well known process classification characteristics are the type of influence, the type of conversion and the type of medium what is distinguished. The type of influence describes the main characteristic of process. There has to be decided whether it is a manufacturing, a distribution or a storage process. More detailed is the type of conversion, which characterizes process engineering, production engineering or handling engineering of the considered industrial process. The type of medium characterizes chemical processes/ material processes, energy processes and information processes. All these characteristics are used for a global classification with high level abstraction. For this reason they are uncertain for process modeling.

To develop a process classification strategy, which is prejudical for a generalization of special hybrid modeling technique, it is necessary to determine several important process characteristics.

In this paper some tables of characteristics are used to classify a special class of industrial processes. For this class of processes a combined modelmodeling technique for implementation of a quality prediction system will be presented. The sintering process for burden preparation in the smeltery industry already mentioned is a process for a practical application of the modeling technique. Beside methods from the computational intelligence like neuro-fuzzy systems, a material flow simulation could be realized which is based on a control systems analysis.

To obtain a more detailed classification for industrial processes it is suggested to use the the following tables of characteristics ${ }^{1}$ :

\section{Table 1: material flow characteristics}

\begin{tabular}{|c|c|c|}
\hline \multicolumn{3}{|c|}{ type of material handling in the plant } \\
\hline continuously & sequentially & batch process \\
\hline
\end{tabular}

\begin{tabular}{|c|c|c|}
\hline \multicolumn{3}{|c|}{ example processes } \\
\hline $\begin{array}{c}\text { petrochemical } \\
\text { industry }\end{array}$ & $\begin{array}{c}\text { varnishing } \\
\text { industry }\end{array}$ & sintering plant \\
\hline
\end{tabular}

1. The grey colored table cells are characterizing the sintering example process
Hereafter the availability of process variables may be classified by the following characteristics:

Table 2: availability of process variables

\begin{tabular}{|c|c|c|c|c|c|}
\hline \multicolumn{6}{|c|}{ availibility and sensing frequency of } \\
influencing variables \\
\hline $\begin{array}{c}\text { available } \\
\text { sensing } \\
\text { points }\end{array}$ & \multicolumn{2}{c|}{$\begin{array}{c}\text { derivated } \\
\text { sensing } \\
\text { variables }\end{array}$} & $\begin{array}{c}\text { sampling } \\
\text { and } \\
\text { anlysis }\end{array}$ & $\begin{array}{c}\text { computed } \\
\text { variable }\end{array}$ \\
\hline $\mathrm{c}^{\mathrm{a}}$ & $\mathrm{s}^{\mathrm{b}}$ & $\mathrm{c}$ & $\mathrm{s}$ & $\mathrm{s}$ & $\mathrm{s}$ \\
\hline
\end{tabular}

\begin{tabular}{|c|c|c|c|}
\hline \multicolumn{4}{|c|}{ example } \\
\hline continu- & content of a & strength & composi- \\
ous meas- & bin plant by & analysis of & tion of bulk \\
uring of a & continuous & bulk & material \\
reactor & weight & material & \\
temperature & measuring & every 4h & \\
\hline
\end{tabular}

a. c: continuously

b. s: sequentially

To improve operational control it is substantially to be able to determine the product quality frequently. The location of measuring or sensing points in the plant is dependent on the actual type of process. For this reason the facility of quality determination is also an important process characteristic.

\section{Table 3: quality determination characteristics}

\begin{tabular}{|c|c|c|}
\hline \multicolumn{3}{|c|}{ facility for quality determination } \\
\hline permanent & $\begin{array}{c}\text { sequentially, in } \\
\text { different loca- } \\
\text { tions of the plant }\end{array}$ & $\begin{array}{c}\text { sequentially, at } \\
\text { the end of } \\
\text { processing } \\
\text { chain only }\end{array}$ \\
\hline \multicolumn{3}{|c|}{ example processes } \\
\hline assembly & chemical & blast furnace \\
\hline
\end{tabular}

Another important characteristic is the delay-time behaviour of the industrial process. The period which is required to pass the material through the processing chain depends on the plant topology. The delay-time characteristic plays an important role for the implementation of a quality prediction system.

Table 4: delay-time behaviour

\begin{tabular}{|c|c|c|c|}
\hline \multicolumn{4}{|c|}{ characteristics of delay-time } \\
\hline \multicolumn{2}{|c|}{$\begin{array}{l}\text { dynamic process with } \\
\text { poor delay-time behav- } \\
\text { iour }\end{array}$} & \multicolumn{2}{|c|}{$\begin{array}{l}\text { slow process with } \\
\text { distinct delay-time } \\
\text { behaviour }\end{array}$} \\
\hline constant & variable & constant & variable \\
\hline \multicolumn{4}{|c|}{ example processes } \\
\hline varnishing & assembly & chemical & sintering \\
\hline
\end{tabular}


Most important for a model implentation is beside the description of relationship between the influencingand the quality relevant target variables, the dimension of these variables. The complexity of model structure depends on these characteristics.

\section{Table 5: influencing relationship}

\begin{tabular}{|c|c|c|c|c|c|c|}
\hline \multicolumn{7}{|c|}{$\begin{array}{l}\text { relationship between influencing- and quality rele- } \\
\text { vant target variables }\end{array}$} \\
\hline \multirow{2}{*}{\multicolumn{2}{|c|}{$\begin{array}{l}\text { by } \\
\text { equation }\end{array}$}} & \multicolumn{4}{|c|}{ in a descriptive manner } & \multirow{3}{*}{$\begin{array}{c}\text { un- } \\
\text { known }\end{array}$} \\
\hline & & \multicolumn{2}{|c|}{ qualitatively } & \multicolumn{2}{|c|}{$\begin{array}{l}\text { qualitatively+ } \\
\text { quantitatively }\end{array}$} & \\
\hline inear & $\begin{array}{l}\text { non- } \\
\text { linear }\end{array}$ & linear & $\begin{array}{l}\text { non- } \\
\text { linear }\end{array}$ & linear & $\begin{array}{l}\text { non- } \\
\text { linear }\end{array}$ & \\
\hline
\end{tabular}

\begin{tabular}{|c|c|c|}
\hline \multicolumn{3}{|c|}{ example processes } \\
\hline rolling mills & $\begin{array}{c}\text { sintering } \\
\text { plants }\end{array}$ & $\begin{array}{c}\text { hydrogena- } \\
\text { tion of } \mathrm{C}_{2}\end{array}$ \\
\hline
\end{tabular}

Table 6: complexity of model

\begin{tabular}{|c|c|c|c|}
\hline \multicolumn{3}{|c|}{$\begin{array}{r}\text { dimension of influencing- and quality relevant target } \\
\text { variables }\end{array}$} \\
\hline $\begin{array}{c}\text { few variables } \\
\text { (small dimension) }\end{array}$ & \multicolumn{2}{|c|}{$\begin{array}{c}\text { many variables } \\
\text { (large dimension) }\end{array}$} \\
\hline $\mathrm{n}: 1$ & $\mathrm{n}: \mathrm{m}$ & $\mathrm{n}: 1$ & $\mathrm{n}: \mathrm{m}$ \\
\hline
\end{tabular}

\begin{tabular}{|c|c|c|c|}
\hline \multicolumn{4}{|c|}{ example processes } \\
\hline $\begin{array}{c}\text { heating } \\
\text { process }\end{array}$ & $\begin{array}{c}\text { hydrogena- } \\
\text { tion of C2 }\end{array}$ & $\begin{array}{c}\text { financial } \\
\text { series } \\
\text { analysis }\end{array}$ & $\begin{array}{c}\text { sintering } \\
\text { process }\end{array}$ \\
\hline
\end{tabular}

Finally the level of automation of the treated industrial process has to be characterized. A high level of automation ensures a reduced range of fluctuations of operations and is prejudical for an improvement of operation plant control.

Table 7: level of automation

\begin{tabular}{|c|c|c|}
\hline \multicolumn{3}{|c|}{ level of automation in the plant } \\
\hline $\begin{array}{c}\text { manually } \\
\text { controlled }\end{array}$ & $\begin{array}{c}\text { partially } \\
\text { automated }\end{array}$ & $\begin{array}{c}\text { completely } \\
\text { automated }\end{array}$ \\
\hline
\end{tabular}

\begin{tabular}{|c|c|c|}
\hline \multicolumn{3}{|c|}{ example processes } \\
\hline recycling & assembly & bulk material \\
\hline
\end{tabular}

Table 8: operational control

\begin{tabular}{|c|c|c|}
\hline \multicolumn{3}{|c|}{ type of operational control in the plant } \\
\hline $\begin{array}{c}\text { manually } \\
\text { controlled }\end{array}$ & $\begin{array}{c}\text { partially } \\
\text { automated }\end{array}$ & $\begin{array}{c}\text { completely } \\
\text { automated }\end{array}$ \\
\hline
\end{tabular}

\begin{tabular}{|c|c|c|}
\hline \multicolumn{3}{|c|}{ example processes } \\
\hline sintering & wastewater & waste \\
plant & treatment & incineration \\
& plant & plant \\
\hline
\end{tabular}

The proposed strategy for process classification by characteristics was used for a classification of a sintering process for iron ore in the smeltery industry. Hereafter a quality prediction system for the example process with a hybrid modeling technique will be implemented.

\section{PROBLEMS IN THE AUTOMATION OF SINTERING PLANTS}

The sintering process is intended to supply to a blast furnace the required quantity of iron ore sinter at the desired quality. Beside a good quality of the sintered material, reduced production costs can be obtained, when the sintering process operation is stabilized. From a control point of view a sintering plant involves an extremely difficult process. The main reasons for this are long delay times in the hour range, the existence of material circuits as well as complex relationships in the area of sinter chemistry and/or sinter physics.

To model the process in a suitable manner:

- the relationship between physical/ chemical variables and the essential quality-relevant variables for the sintered material were elaborated and presented (figure 1)

- the process data collected were correctly assigned in terms of time with the help of a material-flow model which takes into account the dynamic delay times of the plant and

- the models developed by using computational intelligence (CI) methods were trained with such process data.

Based on the results of inquiries with experts [Nam90] and on known relationships, all essential variables,

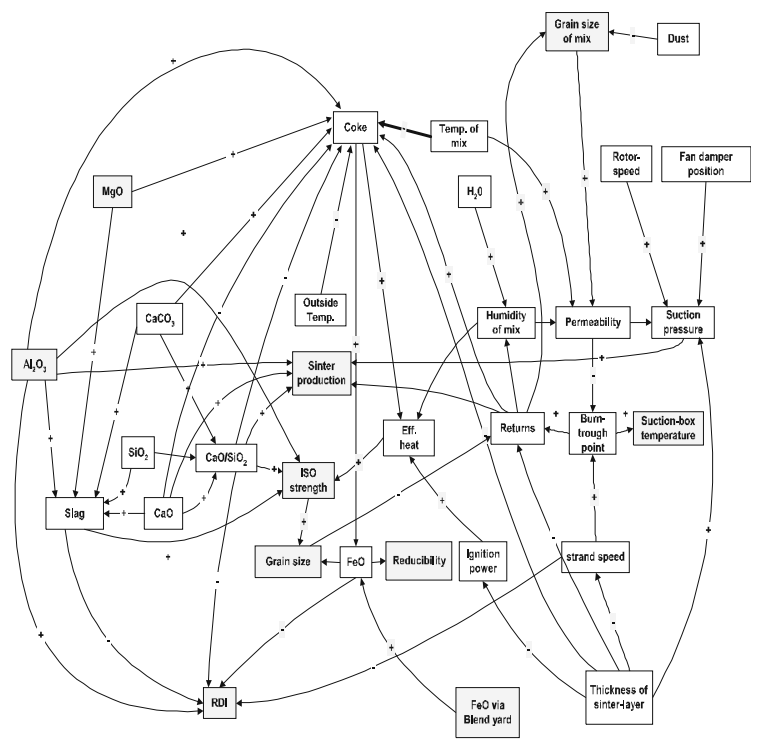

Fig 1. variable relationship of sintered material 
which influence the properties of the sintered material intensively, are represented in a qualitative dependence of each other. In figure 1 a chart describing physical and chemical context and dependencies of influencing variables is shown. Most of the relationships mentioned can be explained in a descriptive manner only, symbolized by "+" or "-" at the connection lines. For example: increasing the amount of burnt lime $(\mathrm{CaO})$ used as flux will lead to increase in the sinter production (higher tonnage). An improved permeability will lead to shifting of the burn-through point in the direction of sinter-mix-charging and increase production. Consequently a mathematical expression respectively a mathematical model is not available. For this reason CI methods such as Neuro-Fuzzy-Inference Systems are one option for system identification.

Combined with process data from production data aquisition, which are necessary to train a Neuro-Fuzzy model, the knowledge of the sintering process may be completed. To be able to implement the influence charts, it is necessary to build subsystems. In figure 2 such a subsystem is shown representing influences on one quality-relevant variable $(\mathrm{FeO})$ and therewith reducability. The dependencies between process variables and other quality-relevant target variables such as burn-through point or grain size can be described in the same manner.

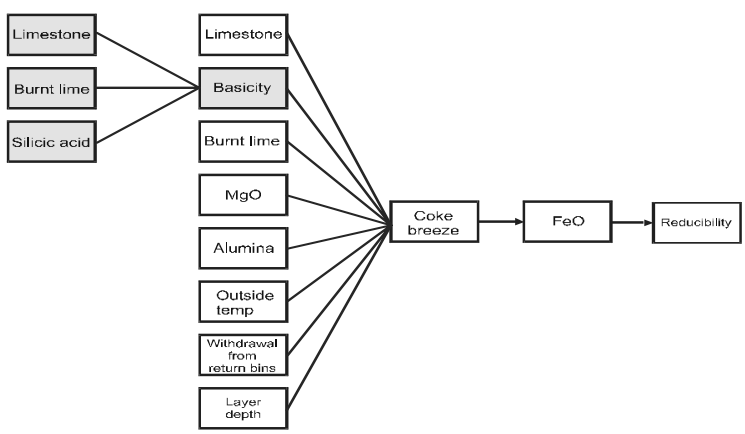

Fig 2. Subsystem for quality variable reducability

As already mentioned at the beginning of chapter 4, process data filed in the plant production computer cannot simply be used for training of the hybrid neurofuzzy system, because the individual data do not correlate with each other in terms of time. A sintered-material capacity of $600 \mathrm{t} / \mathrm{h}$ measured at the outlet of the plant at 03.00 PM must not be assigned to the bin withdrawal rates at $03.00 \mathrm{PM}$ at the input of the plant. The influencing variable ,bin withdrawl rate“ must be shifted by the corresponding delay time relative to the „sintered material capacity“ variable (figure 4). To this end, a suitable delay-time and material flow model of the process has to be developed with the help of a control systems analysis. The process data available in the production computer in tabulated format are read into the model computer and by means of the delay time model are correctly assigned to each other in terms of time. Output of the delay time model are correlated process data which can be used to train the prediction system.

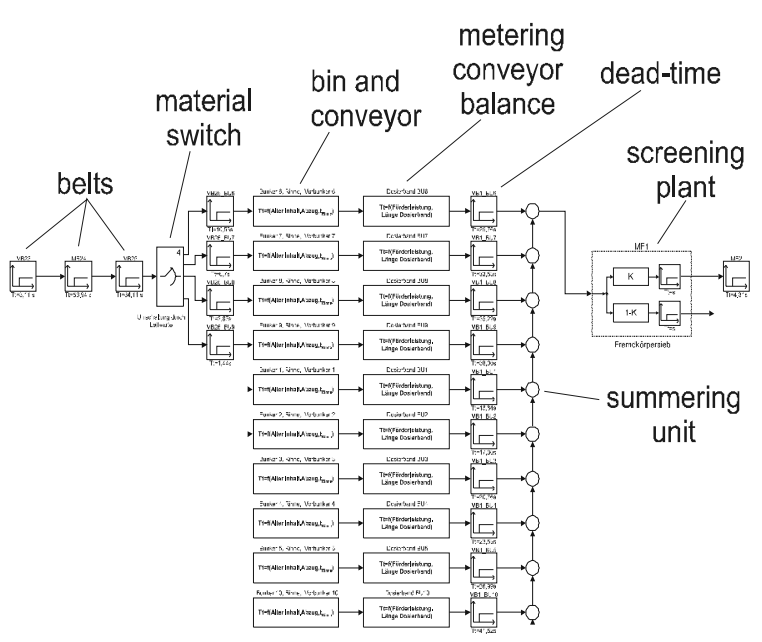

Fig 3. Material flow chart

The results of a control systems analysis are also documented in the standard control systems diagrams. (In figure 3 a part of the material flow chart is presented). This part of the material flow represent the bin facility of the plant with ten main bunker and their subsystems like belts, metering conveyor balances and a screening

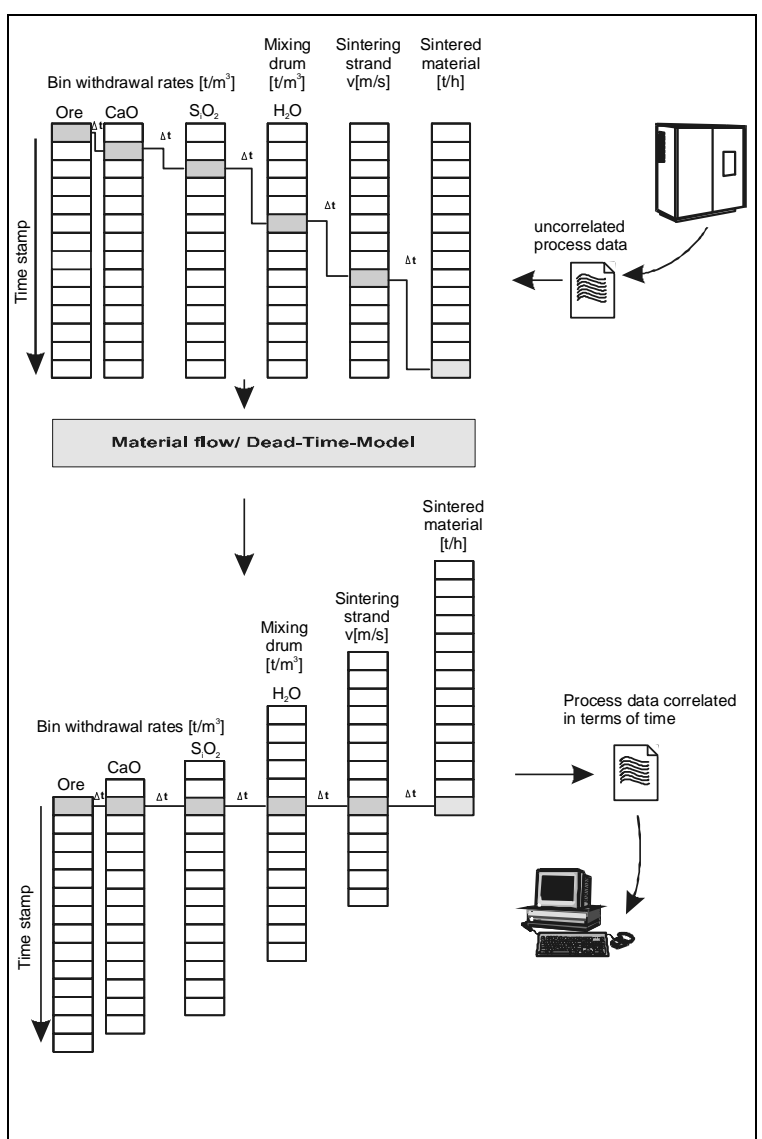

Fig 4. Correlation of process data. 
plant after the computer summering unit. With the knowledge of the material flow (detailed knowledge of various delay-times and effects caused by material circuits in the plant) a tool for correction of process data in terms of time may be devolped.

To realize a software prediction system for sintering quality the knowledge of relationship between the various process variables and the material flow in the plant is fundamental for process modeling and further implementation.

For an implementation of the various models, the utilisation of one suitable common software product would be a desirable improvement. All developed models are represented in PC by means of Matlab/ Simulink ${ }^{1}$ and additional software packages (toolboxes). The presented platform is suitable to be used in a large domain of scientific, mathematical and technical tasks from data analysis (planning) up to modeling and visualization (realization). Equiped with various interfaces the software platform ensures communication with other software modules. For this reason data import and export from other databases or foreign programs is possible without further effort.

Simulink as an interactive tool for modeling, simulating and analysing of dynamic systems is used for representation relationship between variables of the iron ore sintering plant.

As already mentioned in chapter 4 most relationship and influences between process variables can be explained in a descriptive manner only. Due to this fact a hybrid neuro-fuzzy model based on methods of the computational intelligence is proposed. Therefore special toolboxes such as neuro-fuzzy toolbox or neuralnetwork toolbox combined with Matlab/ Simulink are used. Depedencies between process variables can be determined. Membershipfunctions combined with rules deduced from the expert knowledge can be converted without programming effort. Concerning the unknown dependencies a neural network is used to initialize the fuzzy membership functions in width and positioning. Due to this fact a neural network toolbox is used which offers the required methods. To take effect, the neural network has to be trained with process data from the sintering plant. This data has to be preprocessed with the a special software add on. The required algorithm will also implemented to the presented software platform Simulink.

To develop an application for plant process data preprocessing, a model of the material flow has to be developed. Information concerning the flow of bulk material received during the stage of requirements are immediatly converted and placed in the Simulink environment with the graphical user interface combined

1. product by The MathWorks, 3 Apple Hill Drive, Natick with a convenient block library. In figure 5 the bin fa-

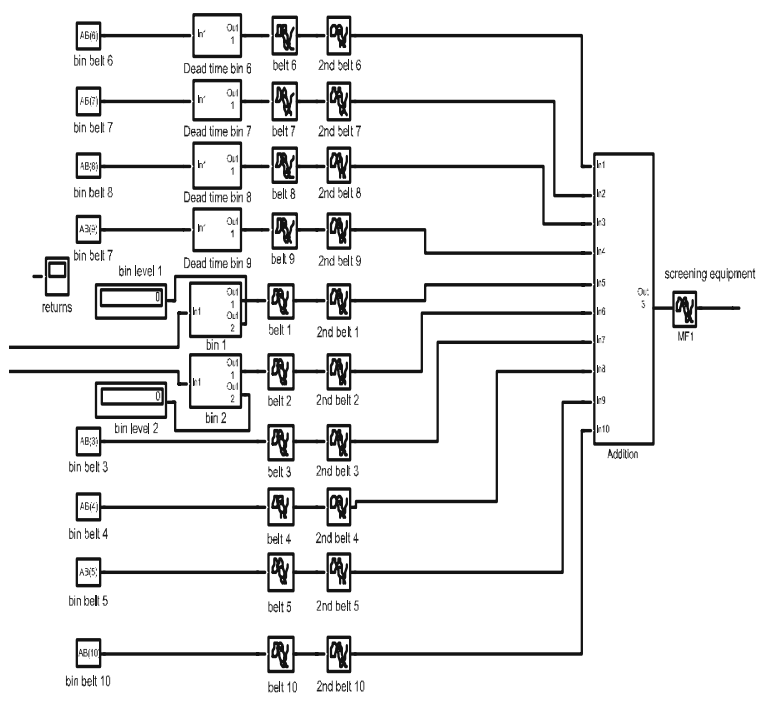

Fig 5. Material flow realized with Simulink

cility of the plant and several supply conveyor belts are illustrated as part of the material flow diagram. Furthermore the influence diagrams describing inner context of physical, chemical and metallurgical relationship (illustrated in figure 1) as the various subsystem deduced from the complete chart can be modeled at the Simulink platform. Therefore the additional toolbox ANFIS ${ }^{2}$ (adaptive fuzzy neural inference system) is needed. This toolbox offers the required CI methods.

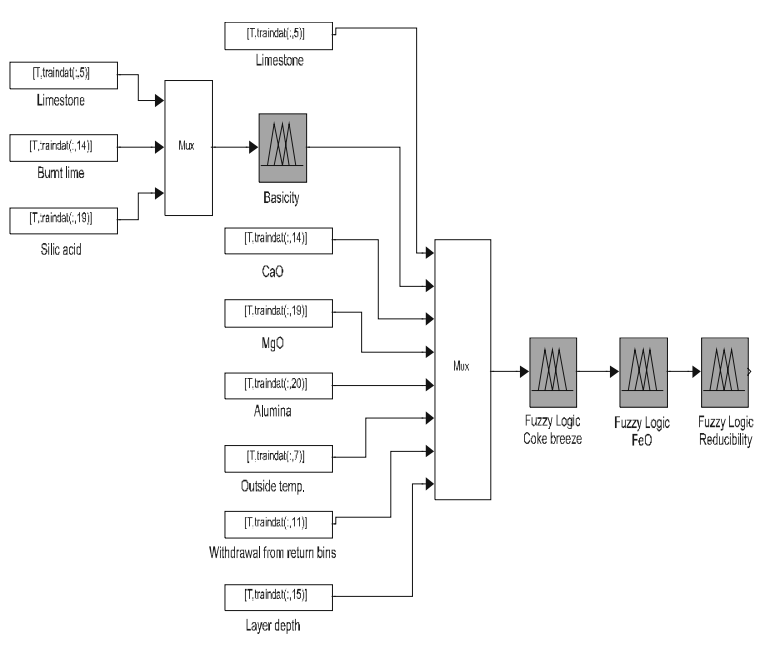

Fig 6. Simulink subsystem for quality variable

The modeled delay-time behaviour of the sintering plant allows to develop a powerful tool which is fundamental for training the neuro-fuzzy model. After implementing this tool and training with process data the composition of sinter respectively some quality re-

2. product by The MathWorks, 3 Apple Hill Drive, Natick 
levant target variables may be predistined. In figure 7 and figure 8 the pre-determination of $\mathrm{FeO}$ and ISOstrength in the sintering material prepared for use in the blast furnace is shown.

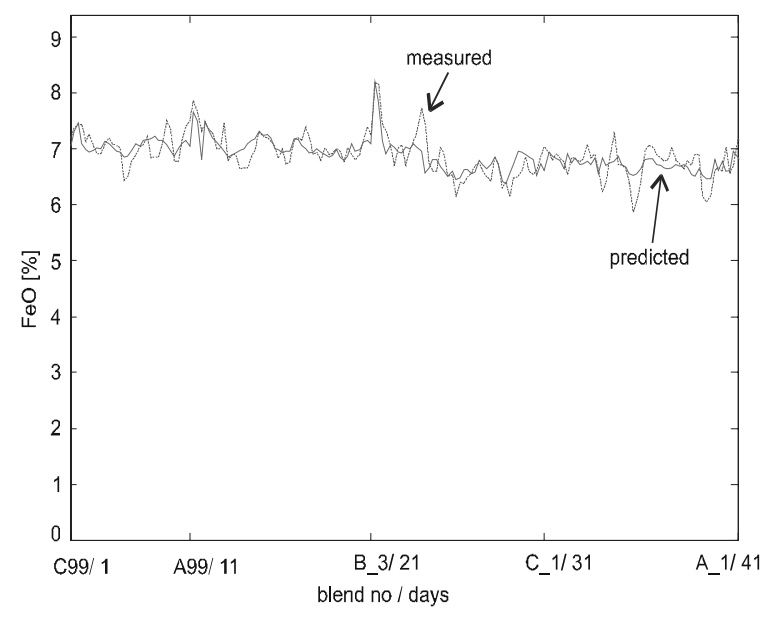

Fig 7. Predicted target value FeO

\section{RESULT}

In this report, a hybrid modeling technique was used for the implementation of a quality prediction system on PC, which assists the operator of an iron ore sintering plant in process control. Before modeling this sintering plant for burden preparation, a strategy for process classification was developed, which allows to determine the special characteristics of an industrial process and to consider these characteristics for the modeling purpose hereafter.

The implemented models are founded on a descriptive relationship between influencing variables and on the results of a control systems analysis. To model the influencing relationship, a neuro-fuzzy system was used, which is trained with process data. The process data are corrected in terms of time by the use of a material flow model. The prediction of the targed variables $\mathrm{FeO}$ and ISO-strength of the sintered material is possible with an acceptable absolute error as shown in figure 7 and figure 8 .

\section{CONCLUSION}

The hybrid modeling technique outlined in this report can be used for implementation of complex quality prediction system. In addition to this, the developed strategy for a process classification makes it possible to use these hybrid methods for an implementation of other quality prediction systems. There are several industrial processes which can be classified with this classification strategy and automated hereafter in the same manner like the sintering process.

\section{REFERENCE}

Booch, G. (1994). Objektorientierte Analyse und Design, Addison-Wesley, Bonn.

Chouika, M., A. Jahnsen and E. Schnieder (1998). Klassifikation und Bewertung von Beschreibungsmitteln für die Automatisierungstechnik. Oldenbourg Verlag, München.

Davis, A.M. (1990). Software Requirements-Analysis and Specification. Prentice hall, Englewood Cliffs, NJ/USA.

Er,M.J., J. Liao, J. Lin (6/2000). Fuzzy Neural Networks-Based Quality prediction System for Sintering Process, volume 8 No. 3, IEEE Transactions on Fuzzy Systems, USA.

Goguen, J.A., C. Linde (1993). Techniques for Requirements Engineering. Proceeding of the International Symposium of Requirements Engineering, Toronto.

Guttag, J., V.Larch (1993). languages and tools for formal specification. Springer Verlag, New York.

Iwamoto, M.(1988). Application of Fuzzy Control for Iron Ore Sintering Process volume 28. Transactions of the iron and steel institute, japan.

Jang, M. (1998). Belt Speed control in a sintering plant using a neural network. Steel research 69, No. 10+11. , VDEH, Düsseldorf.

Namara, M.C., R. Alan, L. Lock and G. Laurie (1990). Experiences in developing an intelligent operator guidance system. Springer-Verlag, Heidelberg.

Nauck N., D. Klawonn and F. Kruse (1994). Neuronale Netze und Fuzzy Systeme. Vieweg, Wiesbaden. 